\title{
The Case Against Intellectual Property
}

\author{
Michele Boldrin and David K. Levine \\ University of Minnesota and UCLA
}

January 14, 2002 


\section{Introduction}

According to a common argument, the presence of strong intellectual property rights spurs innovation, which leads to higher economic growth and increasing benefits for all. The argument seems coherent: the establishment of secure property rights is a fundamental pillar of a well functioning market economy. No economic agent exercises productive effort without the certainty of controlling its fruits. What is true for physical effort must be true for the intellectual one: if strong property rights provide good incentives for the production of potatoes, they must also provide good incentives for the production of ideas.

Why then do we argue a "case against intellectual property?" Are we arguing that, while stealing potatoes is bad, stealing ideas is good? We are not. Economic efficiency, and common sense, argue that ideas should be protected and available for sale, just like any other commodity. But "intellectual property" has come to mean not only the right to own and sell ideas, but also the right to regulate their use. This creates a socially inefficient monopoly, and what is commonly called intellectual property might be better called "intellectual monopoly." When you buy a potato you can eat it, throw it away, plant it or make it into a sculpture. Current law allows producers of a CDs and books to take this freedom away from you. When you buy a potato you can use the "idea" of a potato embodied in it to make better potatoes or to invent french fries. Current law allows producers of computer software or medical drugs to take this freedom away from you. It is against this distorted extension of intellectual property rights that we argue.

It is a long jump from the assertion that inventors deserve the fruits of their efforts to the conclusion that current patent and copyright protection are the best way of providing such reward. Statements such 
as this "A patent is the way of rewarding somebody for coming up with a worthy commercial idea" ${ }^{1}$ abound in the business, legal and economic press. In arguing the case against "intellectual monopoly" we will examine this jump with care.

\section{Downstream Licensing}

Intellectual property, as commonly used, has two components. One is the right to own and sell ideas. The other is the right to control the use of those ideas after sale. The first, sometimes called the right of first sale, we view as essential. The second, which we refer to as downstream licensing, we view as economically dangerous. All producers would impose downstream licensing agreements if they could: producers prefer not to compete against their customers. But the absence of competition leads to monopoly, and economists as a rule frown on monopoly. That the downstream licensing provisions of patent, copyright and other private contracts lead to monopoly is well understood. Among economists the argument has been that it is only through monopoly that it is possible to reward inventive activity. There is a seemingly compelling logic: the cost of innovation is a fixed cost and ideas are distributed at zero, or at least constant, marginal cost. Since perfect competition prices at marginal cost, the fixed cost cannot be recouped. Consequently, if producers of intellectual property are forced to compete with their customers, they will not be able to recoup the cost of creation. This point is forcefully made, for example, in Romer [1990].

In other work [Boldrin and Levine, 2001] we have pointed out that creation is not a fixed but a sunk cost. Since only ideas embodied in

${ }^{1}$ The Economist, June $23^{\text {rd }} 2001$, page 42 ; italics added. 
people or products matter, the cost of creation is the cost of producing the first unit. Such a "sunk cost" is very ordinary in economics, and poses no particular threat to perfect competition. As far as we know there is no organized movement to provide producers of potatoes, or any other commodity involving sunk costs, with a government monopoly. What is different about creative activity is the indivisibility involved in producing the first unit: two half-baked ideas to not equal one fully baked.

The theory of competition with indivisibilities is not yet fully worked out. In Boldrin and Levine [2001] we show that competition often yields the first best; that diminishing costs of replication can increase, rather than decrease, the incentive for creative activity, and that downstream licensing may hurt rather than help innovation. We illustrate these ideas below by means of a simple example.

Never the less, there is an expectation, that we share, that there are cases where ordinary competitive rents will be insufficient reward to induce socially desirable creative activity. In the rest of this essay, we also argue that the monopoly power in downstream licensing has costs that vastly exceed the usual "welfare triangle," and that creative competitive mechanisms can provide the right reward for inventive activity, even where monopoly fails.

\section{Collateral Costs}

Like all property, intellectual property is expensive to protect. However, downstream licensing agreements are especially costly to enforce because they require either the producer or the government to tightly supervise the use of ideas. There are of course the direct costs of writing laws, catching lawbreakers, and bringing legal action against them. However, there are many other forms of "collateral damage" doing harm to economic welfare throughout the economy. Here we focus on ideas 
that can be embodied in digital form, such as computer programs, music, books and movies. To supervise usage of these products requires copy protection technology. Copy protection mandated by law is especially pernicious because the potential economic damage - think of abolishing all computers because they can be used to pirate music bears no relationship to the underlying value that is being protected.

Unless mandated by law, few people will choose to install software that enforces copy protection instead of software that does not. This was recognized, for example, in the case of digital audiotape, where copy protection was legally mandated. Unfortunately, copy protection technology often does not work very well. Digital audio tape recorders that do not work very well do not pose much of an economic threat (except to the users of digital audio tape recorders). However, the same computers that play music, also hold financial records, creative work, email records, and much of economic value. A malfunctioning copy protection system that destroys files, causes computers to crash, or causes other forms of collateral damage can easily have an economic cost far exceeding the value of all recorded music.

The inability to reverse engineer software that enforces copy protection has other collateral costs. If copy protection software is secretly phoning home to provide its issuers with private information about users, this flagrant violation of privacy is difficult or even illegal to prevent. There is also an important commitment problem with copy protected ideas: if the producer goes out of business, the copy-protected products may lose their value. Unfortunately there does not seem to be a credible mechanism by which producers can, for example, commit to putting their software into the public domain if they go bankrupt.

Suppression of ideas through the legal system creates other collateral problems through the impact on research and development. Although 
laws are designed in an effort to minimize this impact, it is a fact that research and development under the watchful eye of a regulatory agent is going to be greatly inhibited. Similar conflicting goals arise in the protection of the freedom of speech and of political discourse. The same technology used to track "music freeloaders" can be used to track individuals who express unpopular opinions, for example.

On the patent front, more time and energy seems to be spent on nuisance and defensive patenting of the obvious or well-known than is spent on actually innovating new ideas. Individuals exploit the relative ignorance of patent examiners by patenting ideas already in wide-spread use in hopes of collecting licensing fees, or at least greenmail, from a few large companies; large corporations patent and cross-license everything imaginable both to protect themselves against greenmail, and to suppress entry into their industry. That cross-licensing and "protection of intellectual property" can be instrumental in promoting collusion within an industry seems transparent. On the empirical side, Gans et al [2000] provide evidence from a 1999 survey of high-tech start-ups that "stronger [intellectual] property protection is associated with higher, rather than lower levels of cooperation between incumbents and start-up innovator entrant."

Ultimately, the modern case against monopoly rests less against the welfare triangle from monopoly pricing than from the rent-seeking activity used to get and keep a monopoly. Unfortunately when government enforced, the collateral costs, externalities imposed on the rest of the economy, are not limited by the value of the property that is being "protected." Government enforcement also poses the well-known problem of regulatory capture. In the case of "intellectual monopoly" capture has extended to the entire U.S. Congress, which has, on numerous occasions, unanimously voted to extend the period of 
copyright retroactively.

\section{Competition without downstream licensing}

We give an example to illustrate the idea in Boldrin and Levine [2001] that innovation can thrive in a competitive economy even in the face of indivisibility. In this economy individuals live forever. There are many consumers, indexed by $c>0$. In each period, consumers either consume one unit of the good, or not. The benefit to consumer c of consuming a unit of the good is $\mathrm{c}^{-\psi}$ with $\psi>0$. In other words, consumers are ordered by how they value the consumption flow of this good: consumers for whom $\mathrm{c}$ is small value it highly. Consumers also prefer to consume early rather than later: a unit of good consumed today is worth $\delta<1$ of a unit of the same good consumed next period. In any period in which the good is not consumed, consumer c receives a payoff equal to zero, independently of how much he/she likes consumption.

Initially, there is a single prototype of the commodity that generates the flow of consumption service. The inventor or producer owns this prototype. For concreteness, assume this is a durable good. Once sold, no downstream licensing is possible. At each moment of time the prototype can either be used to generate a flow of consumption or reproduced. To make things less abstract, let us imagine the new good is a fresh recording of a new musical piece that is embodied in an MP3 file. Each copy takes one period to produce, and each MP3 that is copied produces $\beta>1$ additional MP3's in that period. Our interpretation of a technology such as Napster or Audio Gnome is that it increases $\beta$, that is, the number of MP3's that can be distributed (reproduced) to different consumers from a single master copy in a single time period is greatly increased. 
Under competitive conditions, in the $\mathrm{t}$-th period each MP3 sells for a single market price $q_{\text {. }}$. MP3's may also be rented for a single period for a rental rate $r_{t}$. Notice that consumers for whom $c^{-\psi}>r$ value the song more highly than the rental cost, and will choose to listen to an MP3 that period; consumers for whom $\mathrm{c}^{-\psi}<r_{\mathrm{t}}$ will choose not to listen to the MP3: if they have a copy, they prefer renting out their copy to someone else to listening to it themselves. Notice how in a competitive environment, everyone is potentially a buyer and a seller.

We are interested in two primary questions. Is the price of the very first copy enough to compensate the producer for its sunk cost? Does the price of the first copy increase or decrease when new technologies increase $\beta$ ?

According to standard competitive theory the sale price of an MP3 is just the present value of the rental rates. Since the rental rate is determined by the marginal consumer, it is $p_{0}=\sum_{t=0}^{\infty} \delta^{t} c_{t}^{-y}$ where $c_{t}$ is the number of MP3s that are used for listening in period $t$.

Let $x_{t}$ denote the stock of MP3s in period $t$. Because of the constant elasticity a competitive market will devote a fixed fraction $\phi \in[0,1]$ of MP3's to listening each period, with the remainder used for reproduction of MP3's for next period. Since we start with a single MP3, and since $c_{\mathrm{t}}=\phi \mathrm{x}_{\mathrm{t}}$ we find that

$$
\mathbf{p}_{0}=\sum_{\mathbf{t}=0}^{\infty} \delta^{\mathrm{t}}\left[\phi(1+\beta(1-\phi))^{\mathrm{t} \mathrm{t}^{-\psi}}=\frac{\phi^{-\psi}}{1-\delta(1+\beta(1-\phi))^{-\psi}} .\right.
$$

To conclude our calculation, we need to determine what is the fraction $\phi$ that the market listens to each period, and what is the fraction used for the reproduction and distribution of new MP3's. If, in the initial period an MP3 is used for listening, the value to the marginal listener is $\phi^{-\psi}$. If, instead, the MP3 is used to produce MP3's for next period, next period 
we will have an additional quantity $\beta$ of MP3's. These MP3's will be valued by the marginal listener at $\delta[\phi(1+\beta(1-\phi))]^{-\psi}$. Competition equalizes these marginal values. Solving this equation for $\phi$ and plugging back in to the price relationship gives our bottom line

$$
\mathbf{p}_{0}=\frac{\beta\left(\frac{1+\beta}{\beta}-\delta^{1 / \psi} \beta^{(1-\psi) / \psi}\right)^{-\psi}}{\beta-1}
$$

For finite values of $\beta, p_{0}$ is a positive and finite number. Since $p_{0}$ is what the producer can earn from the first sale when he has no downstream protection at all (in practice he should be able to do better than this), there is money to be made for producers of intellectual products.

Is this competitive value of intellectual products enough to motivate the producers to spend the effort and time required? We do not know. To answer this question one needs to know the particular opportunity cost of time of the particular creator, which clearly varies from case to case. It seems to us, though, there is no hard empirical evidence supporting the view that this value would not be enough.

We also want to understand the social impact of a technology which facilitates the reproduction of "idea-goods". Does it increase or decrease the value of intellectual products in a competitive market? Basically, received wisdom argues that cheap copying makes it impossible for innovators to earn back their production costs. If, in a competitive setting, increasing $\beta$ lowered $p_{0}$ received wisdom would be correct without downstream protection, less "idea-goods" would be created as a result of the advent of the new technology.

What does happen to $\mathrm{p}_{0}$ as the technology as $\beta$ grows larger? The answer depends on $\psi$. If $\psi<1$ demand is elastic. This is the empirically interesting case. As $\beta$ grows larger, it is easy to check from the equation 
above that the fraction $\phi$ goes to zero, so most of it is being used for reproduction of new copies. Consequently, its price goes to infinity. In fact, but this is a special implication of the analytic forms we are using, this happens as $\beta$ approaches a finite value. Notice that in all cases, the rate at which the price falls over time is proportional to $\beta$. Never-the-less with elastic demand and large $\beta$, the dramatic increase in the rate with which price falls over time is associated with a higher initial price and greater rent for the innovator.

In summary, under competition and in the empirically interesting case where demand is elastic, improving the technology for reproduction increases the first sale price without bound: The improved technology makes it much easier for a producer to recover sunk costs in a competitive market. This does not mean that the producer will argue against downstream licensing and in favor of increased competition: she will still be able to earn more revenue with a monopoly than under competition. But it is a good argument for not giving in to the producer and granting them the monopoly: the social benefit of the monopoly (the ability to cover sunk costs and produce a socially desirable good) is reduced by the new technology.

This establishes competitive markets as a viable institutional setting for fostering innovative activity ${ }^{2}$. We move now to consider the viability of alternative institutional settings

${ }^{2}$ In Boldrin and Levine [2001] we develop a more general version of this argument. 


\section{The Hidden Costs of Imperfect Monopoly}

What happens when competitive rent is insufficient to cover the cost of producing the first unit? Let us consider the stark case traditionally considered in economic theory in which there is a fixed cost that must be recovered, and that the marginal cost of production is zero. With demand that is perfectly elastic up to an upper bound, there is no cost of monopoly, so this would seem the ideal environment to impose downstream licensing restrictions.

This is correct only if it is not possible to produce similar items. In the case of textbooks, for example, it is easy to produce books that are sufficiently different to be entitled to a separate copyright, but sufficiently similar as to make no difference to consumers. When there are many firms competing for monopoly rents, and market conditions are such that rents can be obtained even with some degree of competition, the rent seeking behavior of competing monopolists dissipates the social surplus by overproduction of too many similar items. Copyright may do better than no copyright when there is one firm, but not when there are many. Moreover, if we allow greater creativity in the use of markets by having consumers submit contingent bids, then no copyright is unambiguously better than copyright. It should be transparent from what follows that the same argument can be carried out, verbatim in most circumstances, to the case of patents.

We consider two legal environments: one in which consumers are prohibited from reselling, which we refer to as the copyright environment; and one in which downstream licensing agreements are not legally enforceable, which we refer to as the no copyright environment.

Consider an industry of identical firms that each face a fixed cost $\mathrm{F}<1$ and can produce unlimited quantities at marginal cost zero. There 
are $\mathrm{H}$ identical risk neutral consumers; at a price of one or less they demand one unit, and will purchase nothing at price higher than one. In addition consumers who make a purchase can themselves produce additional units at a marginal cost of $\xi \geq 0$. This can represent the fact that consumers have access to an inferior reproduction technology, that consumers have a preference for buying from the original producer, or, as we described above, that in a setting where production takes time, the seller of the original unit can claim a possibly substantial rent.

In the copyright environment, let $p(N)$ be the post-entry price when $N$ firms have chosen to enter the market. As a simple model of post-entry competition, suppose that $\mathbf{p}(\mathrm{N})=\min \{1,(1-\alpha(\mathrm{N})) \mathrm{NF} / \mathrm{H}+\alpha(\mathrm{N})\}$, where $\alpha(\mathrm{N})>0$. That is, post-entry price lies between the price needed to recover costs (for each firm) and the monopoly price in a way that depends on the number of firms and consumers. In this case entry will occur until $N$ is so large that $(N+1) F / H>1$, while $N F / H \leq 1$. For convenience let us suppose that there is actually an $\mathrm{N}=\mathrm{H} / \mathrm{F}$; then this will be the equilibrium number of firms, and the social surplus will be zero, as the total benefit to consumers will be equal to the cost of production. This particular form of market arrangement, call it "copyright induced competition for niches", results in what we can describe as the Pareto worst outcome.

In the no copyright environment, after the first unit of the good is sold, competition among consumers will force the price to $\mathrm{p}=\xi$. If $\xi \mathrm{H}<\mathrm{FN}$ there will be no output and no social surplus. Otherwise the number of firms will be such that $(N+1) F>\xi H$ and $N F \leq \xi H$. Assuming that there is actually an $N=(\xi \mathrm{H}) / \mathrm{F}$ this will be the equilibrium number of firms, and the social surplus will be $\mathrm{H}(1-\xi)$. Without copyright social surplus is never lower and sometimes higher than with copyright.

The contractual environment considered above excludes the important 
possibility that consumers may submit contingent bids prior to production.

We consider only symmetric equilibria in which all consumers submit the same contingent bid. With contingent bids and many firms there is a coordination problem because consumers must decide which producers to submit their bids to. After bids are submitted, let us suppose that firms are ordered by the number of bids they receive, and let b(i) be the number of bids received by firm $i=1, \ldots, N$. We assume that these are fixed numbers satisfying

$$
\sum_{i=1}^{N} b(i)=H,
$$

and that we have ordered them in such a way that $b(i)>b(i+1)$.

In the no copyright environment, suppose that $\mathrm{H} \xi<\mathrm{NF}$ and that that all consumers bid $\mathrm{p}$ where $\mathrm{b}(1) \mathrm{p}+(\mathrm{H}-\mathrm{b}(1)) \xi=\mathrm{F}$. Then the first producer exactly recovers production costs by accepting all bids made to him and selling to the remaining consumers at the price $\xi$. No other producer can earn a profit by entering. Consumers expected utility is exactly $1-\mathrm{F} / \mathrm{H}$ since they are risk neutral, so they are willing to bid $p$. In addition if any consumer bids less than $p$ the good is not produced at all, and he is strictly worse off. Finally, there is no equilibrium with a higher value of $p$ since then each consumer could bid less and still have the bid accepted.

Finally, consider the copyright environment. If $\mathrm{b}(1)=\mathrm{H}$ so there is no coordination problem, then it is an equilibrium for all consumers to bid $\mathrm{F} / \mathrm{H}$ and the first best is obtained. Suppose, however, that $(\mathrm{N}+1) \mathrm{F}>\mathrm{H}$, while $\mathrm{NF}<\mathrm{H}$, so that the equilibrium without contingent bids is strict. Since there can be no more than $\mathrm{N}$ firms producing in any equilibrium, regardless of whether firms accept or reject bids, the effect on demand is at most $\mathrm{Nb}(1)$. Consequently if $\mathrm{b}(1)$ is small enough the equilibrium 
number of firms will remain $\mathrm{N}$ and the equilibrium with contingent bids will be essentially the same as the equilibrium without contingent bids, and similarly inefficient.

\section{References}

Boldrin. M. and D.K.Levine (2001), "Perfectly Competitive Innovation", mimeo, University of Minnesota and UCLA.

Gans, J.S, D.H. Hsu and S. Stern (2000), "When does Start-Up Innovation Spur the Gale of Creative Destruction?", N.B.E.R. Working Paper No. W7851.

Romer, P. (1990), "Are Nonconvexities Important for Understanding Growth", American Economic Review Papers \& Proceedings. 